\title{
USO DO TDR 300 NA DETERMINAÇÃO DA UMIDADE VOLUMÉTRICA DO SOLO PARA MANEJO DA IRRIGAÇÃO DA SOJA SAFRINHA
}

\author{
Mario Santos Nunes ${ }^{1}$, Adroaldo Dias Robaina ${ }^{1}$, Márcia Xavier Peiter ${ }^{1}$, Fabiano De Vargas \\ Arigony Braga ${ }^{1}$, Jardes Bragagnolo ${ }^{2}$
}

\footnotetext{
${ }^{1}$ Universidade Federal de Santa Maria, e-mail: ms.nunes77@bol.com.br, robaina@smail.ufsm.br, mpeiter@gmail.com, fabianovab@gmail.com

${ }^{2}$ Universidade Regional Integrada do Alto Uruguai e das Missões URI Erechim, e-mail jardesb@yahoo.com.br
}

\section{RESUMO}

Objetivou-se avaliar a validade dos dados de umidade volumétrica fornecidos pelo instrumento TDR - "Time Domain Reflectometer" em comparação com o método padrão da estufa, para as camadas $0-7,6,0-12$ e $0-20 \mathrm{~cm}$ de um Latossolo Vermelho Distrófico de textura argilosa nos horizontes A e B, sob plantio direto de soja irrigada. O método avaliado TDR 300 foi capaz de estimar valores de umidade volumétrica do solo com alto grau de confiabilidade por meio da análise de correlação com o método padrão (padrão estufa). O método do sensor de umidade do solo TDR 300 demonstra ser um instrumento rápido e eficaz na determinação da umidade do solo para manejo da irrigação.

Palavras-chave: Solo, camada, pivô central, sensor de umidade

\section{USE OF TDR 300 TO DETERMINATE THE SOIL VOLUMETRIC MOISTURE FOR MANAGING IRRIGATION OF THE SOYBEAN "SECOND SEASON"}

\begin{abstract}
This paper evaluates the validity of data provided by the volumetric moisture instrument "Time Domain Reflectometer" (TDR) compared to the standard oven method, for the layers 0 7.6, 0-12 and $0-20 \mathrm{~cm}$ of a Clayish Oxisoil under tillage irrigated soybean crop. The method TDR 300 was able to estimate values of volumetric soil moisture with a high degree of reliability by analysis of correlation with the standard method (oven standard). The method of the TDR 300 soil moisture sensor proves to be a fast and effective tool to determine soil moisture for irrigation management.
\end{abstract}

Keywords: Soil, layer, center pivot, humidity sensor 


\section{INTRODUÇÃO}

A água disponível para as plantas é um dos principais fatores relevantes para a produtividade das culturas. As plantas absorvem a água que está disponível no solo e práticas de manejo das culturas visam promover condições ideais para o desenvolvimento do sistema radicular e das plantas. Na agricultura uma das atividades que necessita ser melhor manejada, é a irrigação, que pode ser monitorada medindose a umidade do solo diretamente por pesagem e, indiretamente, por meio de tensiômetros, sensores de umidade e sonda de nêutrons, além de outros métodos (TRINTINALHA et al., 2001; MORAES, 2005).

O conhecimento do "status" da água no solo é de importância primordial, uma vez que é permitido um manejo correto desse fator de produção agrícola em áreas irrigadas, isto é, propicia a estimativa do momento e da quantidade de água que deve ser fornecida ao solo para a manutenção do cultivo sob condições hídricas adequadas, na busca da maximização da produtividade.

Portanto, objetivou-se avaliar o grau de confiabilidade de dados obtidos com o TDR (Time Domain Reflectometer) e comparar com o método padrão da estufa, para determinação da umidade do solo e estabelecimento do manejo da irrigação com o sistema pivô central, em uma lavoura cultivada com soja na região central do Estado do Rio Grande do Sul.

\section{MATERIAL E MÉTODOS}

O trabalho foi desenvolvido na região central do Estado do Rio Grande do Sul, em uma área localizada nas coordenadas $29^{\circ} 05^{\prime} 50^{\prime \prime} \mathrm{S}$ e $54^{\circ} 51^{\prime} 32^{\prime \prime} \mathrm{O}$, a uma altitude de 439 metros. O solo da área de cultivo é classificado como Latossolo Vermelho distrófico típico, unidade de mapeamento Cruz Alta com textura argilosa nos horizontes A e B (EMBRAPA, 2006).

O estabelecimento da cultura da soja safrinha foi efetuado no dia 14 de janeiro de 2013 com a variedade Munasqa, sob semeadura direta após a cultura do milho com aproximadamente 18 sementes por metro linear e fileiras de $0,33 \mathrm{~m}$.

Para controle da umidade do solo foi utilizado como método de referência o método padrão da estufa (TRINTINALHA et al., 2001) sendo realizado no período de 25 de março a 24 de abril do ano de 2013, com intervalos irregulares conforme a demanda hídrica da cultura levando-se em consideração as precipitações ocorridas na área experimental. 
Juntamente com as determinações de umidade do solo pelo método padrão da estufa foram realizadas as determinações com o método de sensores utilizando o TDR 300 (TDR $300^{\circledR}$ - Fildscout). Antes do início da realização das coletas de umidade do solo foi feita uma calibração do aparelho TDR, obedecendo as recomendações do manual do aparelho.

Após a coleta, armazenamento e processamento dos dados obtidos com o TDR foi determinada a porcentagem de umidade média de todo o local do experimento. Para comparação dos dados de umidade com o método padrão estufa, utilizou-se o TDR com as hastes de 7,6 cm, $12 \mathrm{~cm}$ e $20 \mathrm{~cm}$ buscando avaliar os perfis de solo onde se encontra a maior parte do sistema radicular da soja.

$\mathrm{Na}$ coleta das amostras de solo para determinação da umidade pelo método padrão da estufa utilizou-se um trado, retirando-se amostras de solo sempre no mesmo horário (15 horas e 30 minutos). Após a retirada das amostras de solo, as mesmas eram embaladas em recipientes plásticos para evitar a perda de umidade e identificadas. Seguindo o procedimento padrão para o método (OLIVEIRA \& RAMOS, 2008) as amostras foram destorroadas e uma alicota de aproximadamente $100 \mathrm{~g}$ de cada foi levada a estufa a uma temperatura de $105^{\circ} \mathrm{C}$ por um período de 24 horas ou até atingir peso constante. Após as amostras atingirem o peso constante calculou-se a porcentagem de umidade para menejo da irrigação.

Os resultados experimentais foram submetidos à análise descritiva e de variância. As médias foram comparadas pelo teste de Tukey a 5\% de probabilidade de erro, através do pacote estatístico ASSISTAT 7.7 Beta.

\section{RESULTADOS E DISCUSSÃO}

Avaliando-se os resultados de porcentagem de umidade do solo para manejo da irrigação obtidos por meiodos métodos foi possível detectar considerável discrepância entre as diferentes camadas de solo (Tabela 1). Resultados semelhantes foram encontrados por (JUNIOR et al., 2011; SILVA, 1998; COELHO et al., 2001; TOMMASELLI \& BACHI, 2001).

Com base nos resultados observados (Tabela 1) detectou-se valores de umidade maiores na camada de $0-7,6 \mathrm{~cm}$ do que nas demais, sendo motivado pelo constante umedecimento proporcionado pelas irrigações e a manutenção permanente de cobertura morta do solo proveniente do 
plantio direto, desta forma a averiguação da umidade do solo deve ser realizada em amostragens abrangendo todas as camadas de solo.

De acordo com Costa et al. (2003), nas camadas superficiais do solo a umidade é mais acentuada devido ao manejo do solo utilizado ser o plantio direto, no qual a palha torna-se uma estratégia eficiente para a manutenção da umidade do solo.

Vieira \& Muzilli (1984) concluíram que a diferença entre o plantio direto e outros sistemas de preparo reside no fato de que a superfície do solo neste sistema é protegida por camada de cobertura morta não revolvida, apresenta estrutura rígida, mais resistente à deformação que a camada superficial em sistema de preparo com revolvimento. Além disso, após uma chuva, o solo no plantio direto permanece, com graus mais elevados de umidade por maior período de tempo.

Teixeira et al. (2005), trabalhando com desempenho de TDR na determinação da umidade do solo em perfis mais profundos $(70 \mathrm{~cm})$, encontram resultados de $0,47 \mathrm{~m}^{3} \mathrm{~m}^{-3}$. Já Garzella (2004), avaliou em campo o desempenho de um TDR para determinação de umidade volumétrica do solo e encontrou valores de até $0,34 \mathrm{~m}^{3} \mathrm{~m}^{-3}$ nas primeiras avaliações para camadas mais superficiais.

Os métodos de determinação de umidade apresentaram elevada correlação nas distintas profundidades avaliadas (Figura 1), demonstrando que o método do TDR pode ser utilizado para qualquer camada de solo, desde as mais superficiais até as mais profundas.

Tabela 1. Análise umidade do solo em diferentes camadas do solo pelos métodos padrão da estufa e TDR (Santiago-RS, 2014).

\begin{tabular}{ccc}
\hline Camadas $(\mathrm{cm})$ & Estufa & TDR \\
\hline $0-7,6$ & $30,45 \mathrm{aA}$ & $37,64 \mathrm{aA}$ \\
$0-12$ & $19,61 \mathrm{bA}$ & $21,00 \mathrm{bA}$ \\
$0-20$ & $21,00 \mathrm{bA}$ & $20,99 \mathrm{bA}$
\end{tabular}

Valores seguidos da mesma letra maiúscula na linha não diferem entre si pelo teste de Tukey a $5 \%$ de probabilidade de erro. Valores seguidos de letras minúscula diferentes na coluna diferem entre si pelo teste de Tukey a 5\% de probabilidade de erro. 

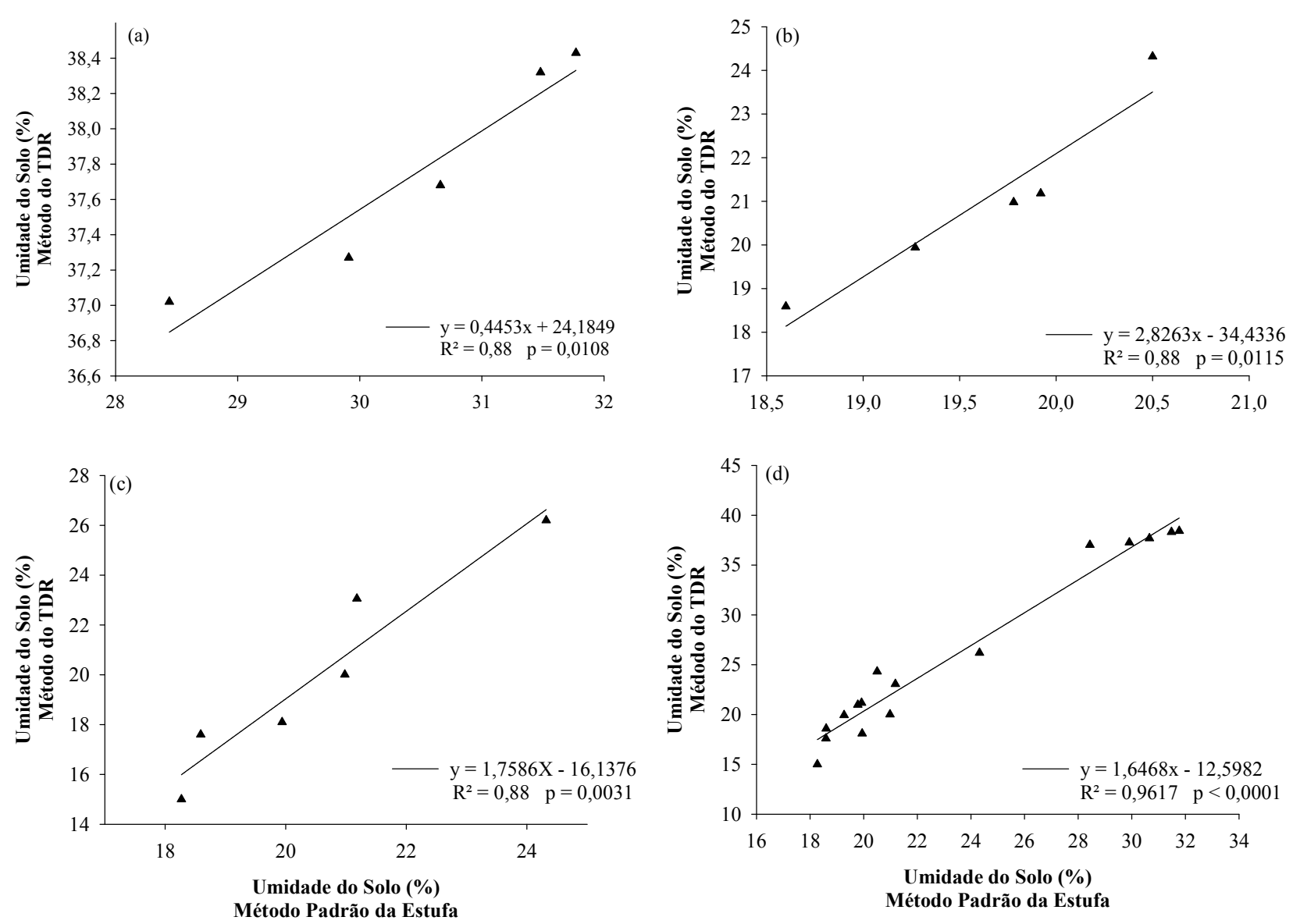

Figura 1. Determinação da umidade do solo pelo método padrão da estufa e método do TDR em uma lavoura de soja safrinha irrigada por pivô central (Santiago-RS, 2014).

O método de avaliação com o sensor de umidade TDR 300 apresentou elevada correlação das determinações de umidade do solo com o método padrão da estufa na área utilizada para cultivo da soja safrinha irrigada com pivô central. Trintinalha et al. (2001), Garzella et al. (2004) e Lacerda (2005) encontraram resultados semelhantes proporcionando praticidade na hora da coleta de dados na área experimental.
O método mostrou-se eficaz na determinação da umidade do solo em diferentes profundidades e altamente correlacionado com o método padrão da estufa.

\section{CONCLUSÕES}

O método do TDR pode ser utilizado para a determinação de lâminas para manejo da irrigação, uma vez que possibilita a determinação de maior número de coletas 
distribuidas na área de cultivo de forma

prática e com elevada acurácia.

\section{REFERÊNCIAS BIBLIOGRÁFICAS}

COELHO, E.F.; ANDRADE, C.L.T.; OR, D.; LOPES, L.C.; SOUZA, C.F. 2001. Desempenho de diferentes guias de ondas para uso com o analisador de umidade TRASE. Revista Brasileira de Engenharia Agrícola e Ambiental, Campina Grande, v.5, n.1, p.81-87.

COSTA, F.S.; ALBUQUERQUE, J.A.; BAYER, C.; FONTOURA, S.M.V.; WOBETO, C. 2003. Propriedades físicas de um latossolo bruno afetadas pelos sistemas plantio direto e preparo convencional. Revista Brasileira de Ciência do Solo, Viçosa, v.27, n.3,p.527-535.

EMPRESA BRASILEIRA DE PESQUISA AGROPECUÁRIA - EMBRAPA. 2006. Centro Nacional de Pesquisa de Solos. Sistema brasileiro de classificação de solos. Rio de Janeiro, 306p.

GARZELLA, T.C.; MOLIN, J.P. 2004. Avaliação em campo de um TDR para determinação de umidade. In: $\mathbf{1 2}^{\mathbf{0}}$ Simpósio Internacional de Iniciação Científica da USP, Resumos, Piracicaba.

JUNIOR, G. V.; CAVALCANTI, M.L.F.; LACERDA, R.D.; GUERRA, H.O.C. 2011. Acurácia de dois TDR na determinação do conteúdo de água de um argissolo. Caderno de Geografia, Belo Horizonte, v.21, n.35, p.74-87.

LACERDA. R.D. 2005. Avaliação de um TDR para determinação do conteúdo de água do solo. Revista de Biologia e Ciências da Terra, Paraíba, v.5, n.1, $12 p$.

MORAES, N.B; MEDEIROS; J.F.; LEVIEN; S.L.A.; OLIVEIRA; A.M.S. 2006. Avaliação de cápsulas de cerâmica e instrumentos de medida de tensão usados em tensiômetros. Revista Brasileira de Engenharia Agrícola e Ambiental, Campina Grande, v.10, n.1, p.58-63.

OLIVEIRA, R.A.; RAMOS, M.M.2008. Manual do Irrigâmetro. UFV, Viçosa, $144 \mathrm{p}$.

SILVA, E.L. da.1998. Determinação automática do teor de água em Latossolo Roxo Distrófico com uso da Reflectometria de Onda. XXVII Congresso Brasileiro de Engenharia Agrícola. Anais. Vol.1, 1998. UFLA/SBEA, Poços de Caldas, p.154156.

TEIXEIRA， C.F.A.; MORAES， S.O.; SIMONETE, M.A. 2005. Desempenho do tensiômetro, TDR e sonda de nêutrons na determinação da umidade e condutividade hidráulica do solo. Revista Brasileira de Ciência do Solo, Viçosa, v.29, n.2, p.161-168.

TOMMASELLI, J.T.G.; BACHI, O.O.S. 2001. Calibração de um equipamento de TDR para medida da umidade de solos. Pesquisa Agropecuária Brasileira, Brasília, v.36, n.9, p.1145-1154.

TRINTINALHA, M.A; GONÇALVES, A.C.A.; FOLEGATTI, M.V.; TORMENA, C.A.; BERTONHA, A.; TSUKADA, J. 2001. Efeito da instalação e da variabilidade entre sondas no uso da técnica de TDR em um Nitossolo Vermelho Distroférrico. Acta Scientiarum, Maringá, v.23, n.5, p.1165-1171.

VIEIRA, M.J.; MUZILLI, O. 1984. Características físicas de um Latossolo Vermelho-Escuro sob diferentes sistemas de manejo. Pesquisa Agropecuária Brasileira, Brasília, v.19, n. 7, p.873-882.

Recebido em: 4/11/2014 Aceito para publicação em: 9/12/2015 